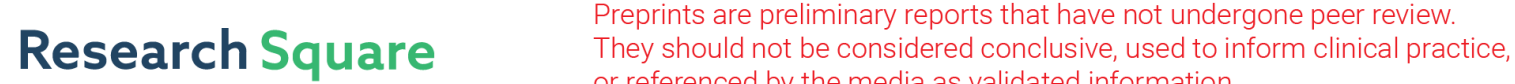 or referenced by the media as validated information. \\ Performance of The Decarboxylation Index To Predict $\mathrm{CO}_{2}$ Removal And Mechanical Ventilation Reduction Under V-ECMO Or High-Flow $\mathrm{ECCO}_{2} \mathrm{R}$
}

Thomas Laumon ( $\nabla$ t-laumon@chu-montpellier.fr )

Lapeyronie University Hospital

\section{Elie Courvalin}

Lapeyronie University Hospital

Geoffrey Dagod

Lapeyronie University Hospital

Pauline Deras

Lapeyronie University Hospital

Mehdi Girard

Lapeyronie University Hospital

Orianne Martinez

Lapeyronie University Hospital

Camille Maury

Lapeyronie University Hospital

Hugues Weber

Lapeyronie University Hospital

\section{Xavier Capdevila}

Lapeyronie University Hospital

Jonathan Charbit

Lapeyronie University Hospital

\section{Research Article}

Keywords: Decarboxylation, extracorporeal membrane oxygenation, ECCO2R, ARDS, COPD

Posted Date: January 11th, 2022

DOI: https://doi.org/10.21203/rs.3.rs-1223135/v1

License: (9) (1) This work is licensed under a Creative Commons Attribution 4.0 International License.

Read Full License 


\section{Abstract}

Background: Optimal decarboxylation dose under extracorporeal respiratory support to ensure sufficient reduction of mechanical ventilation stress remains unclear and understudied. The aim of this study was to assess the interdependence of blood flow (BF) and gas flow (GF) in predicting $\mathrm{CO}_{2}$ removal and mechanical ventilation reduction (MVR) under extracorporeal respiratory support.

Methods: All patients who benefited from veno-venous ECMO (HLS-maquet 7.0, $1.8 \mathrm{~m}^{2}$ ) and high-flow $\mathrm{ECCO}_{2} \mathrm{R}$ (HLS-maquet 5.0,1.3 $\mathrm{m}^{2}$ ) in our intensive care unit over a period of 18 months were included. $\mathrm{CO}_{2}$ removal was calculated from inlet/outlet blood gases performed in clinical practice during the first 7 days of oxygenator use. The relationship between the $\mathrm{BF} \times \mathrm{GF}$ product and $\mathrm{CO}_{2}$ removal or MVR was studied using linear regression models.

Results: Eighteen patients were analysed, corresponding to 24 oxygenators and 261 datasets. $\mathrm{CO}_{2}$ removal was $393 \mathrm{~mL} / \mathrm{min}$ (IQR, 310-526 mL/min) for $1.8 \mathrm{~m}^{2}$ oxygenators and $179 \mathrm{~mL} / \mathrm{min}$ (IQR, 165$235 \mathrm{~mL} / \mathrm{min}$ ) for $1.3 \mathrm{~m}^{2}$ oxygenators. The decarboxylation index was associated linearly with $\mathrm{CO}_{2}$ removal $\left(R^{2}=0.62\right.$ and $R^{2}=0.77$ for the two oxygenators, respectively) and MVR $\left(R^{2}=0.72\right.$ and $R^{2}=$ 0.62 , respectively). Values in the range $20-30 \mathrm{~L}^{2} / \mathrm{min}^{2}$ were associated with an MVR ratio between $38 \%$ and $58 \%$ for $1.8 \mathrm{~m}^{2}$ oxygenators, and between $37 \%$ and $55 \%$ for $1.3 \mathrm{~m}^{2}$ oxygenators.

Conclusion: The decarboxylation index is a simple parameter to predict $\mathrm{CO}_{2}$ removal and MVR under extracorporeal respiratory support. A BF of $2 \mathrm{~L}^{2} / \mathrm{min}^{2}$ or more may be necessary to obtain a significant reduction of mechanical convection.

Trial Registration: Being a retrospective study, no trial registration was made.

\section{Background}

The use of veno-venous extracorporeal membrane oxygenation (vv-ECMO) as respiratory support for acute critical pulmonary alterations is increasing. ${ }^{1}$ In this context, vv-ECMO allows the normalization of gas exchanges and might also reduce ventilator-induced lung injuries (VILI) and biotrauma by applying ultraprotective ventilation. ${ }^{2,3}$ Using this method of extracorporeal respiratory support, oxygen $\left(\mathrm{O}_{2}\right)$ and carbon dioxide $\left(\mathrm{CO}_{2}\right)$ are transferred following Fick's law through a semi-permeable polymethylpenthene membrane separating a pump-driven extracorporeal blood flow (BF) and a sweep gas flow (GF). Many parameters influence gas exchanges and affect blood oxygenation and decarboxylation differently. The main parameters of systemic oxygenation are the oxygen gas mix, BF/cardiac output ratio, extracorporeal blood flow recirculation and the importance of a pulmonary shunt. ${ }^{4,5}$ Thus, maintaining systemic oxygenation may be challenging in extreme cases despite a high BF in the case of significant recirculation, high cardiac output and/or massive intrapulmonary shunt. In contrast, extracorporeal blood decarboxylation is reputed to be simpler to achieve using a lower BFs. ${ }^{6}$ Historically, vv-ECMO was 
designed to treat refractory hypoxemia, and different extracorporeal devices using smaller BFs were developed to allow $\mathrm{CO}_{2}$ removal (extracorporeal $\mathrm{CO}_{2}$ removal $\left.\left[\mathrm{ECCO}_{2} \mathrm{R}\right]\right){ }^{7-9}$ Thus, $\mathrm{ECCO}_{2} \mathrm{R}$ strategies were proposed in the treatment of acute exacerbations of chronic obstructive pulmonary disease to avoid endotracheal intubation. ${ }^{10}$ Refractory hypercapnia or application of ultraprotective ventilation was another use in ventilated patients affected by acute respiratory distress syndrome (ARDS). ${ }^{11,12}$ Thus, both $\mathrm{vv}$-ECMO and $\mathrm{ECCO}_{2} \mathrm{R}$ are extracorporeal respiratory support systems that allow blood decarboxylation, but their importance is variable depending on the kind of device used.

Many determinants of extracorporeal blood decarboxylation have been described in previous works: the oxygenator surface and its intrinsic proprieties (i.e., shape, intra-oxygenator recirculation rate, and dead space), blood content of $\mathrm{CO}_{2}$ in the drainage cannula, but especially the $\mathrm{BF}$ and $\mathrm{GF} .^{13-15}$ Using a low BF ( $<1 \mathrm{~L} / \mathrm{min}$ ), GF has a logarithmic association with $\mathrm{CO}_{2}$ removal. ${ }^{16,17}$ In this setting, the main limiting parameter of blood decarboxylation is the low value of extracorporeal circulation flow. In contrast, using higher $\mathrm{BFs}$ (i.e., vv-ECMO or high-flow $\mathrm{ECCO}_{2} \mathrm{R}$ ), the association between $\mathrm{GF}$ and $\mathrm{CO}_{2}$ removal is linear. ${ }^{18}$ Based on this rationale, several authors have proposed using the GF/BF ratio to predict decarboxylation, which has also been reported to be linearly associated with $\mathrm{CO}_{2}$ removal. However, the GF/BF ratio depends on the value of $\mathrm{BF}$, leading to great variability in the value of $\mathrm{CO}_{2}$ removal for a given $\mathrm{GF} / \mathrm{BF}$ ratio. To understand the decarboxylation dose, it would seem more logical to consider the interdependence of the two variables, GF and BF, as previously proposed by Lehle et al. ${ }^{19}$; thus the product of $\mathrm{BF}$ and GF may be a more relevant variable to predict $\mathrm{CO}_{2}$ removal. Surprisingly, to our knowledge, this simple parameter has never been studied directly. In the present study, we therefore hypothesized that BF $\times$ GF would be the central determinant of blood decarboxylation under extracorporeal respiratory support with vv-ECMO or high-flow $\mathrm{ECCO}_{2} \mathrm{R}$.

The main goal of the present study was to assess the performance of $\mathrm{BF} \times \mathrm{GF}$, named the decarboxylation index in our work, to predict extracorporeal $\mathrm{CO}_{2}$ removal and minute ventilation reduction under vv-ECMO and high-flow $\mathrm{ECCO}_{2} \mathrm{R}$.

\section{Materials And Methods}

\section{Study Design and Patients}

After obtaining local ethics committee agreement (IRB number 202000662, Montpellier University Hospital), all patients who benefited from extracorporeal respiratory support by vv-ECMO or high-flow $\mathrm{ECCO}_{2} \mathrm{R}$ (i.e., $\mathrm{BF} \geq 2 \mathrm{~L} / \mathrm{min}$ ) in our critical care unit between January 2018 and July 2020 were assessed retrospectively for the present study. Exclusion criteria were minors, pregnancy, an ongoing juridic protection, and premature death within the first $24 \mathrm{~h}$ after the initiation of extracorporeal respiratory support. 


\section{Management of Patients}

The pattern of extracorporeal respiratory support was chosen in our cohort according to the clinical context. Details of specific indications, devices used, cannulation procedures, specific management, monitoring, anticoagulation protocol and weaning of extracorporeal respiratory support are presented in Supplemental Digital Content 1. Briefly, patients who were hypoxemic, including cases of severe ARDS, benefited from vv-ECMO therapy using a femoro-jugular configuration as first line: 25-29 Fr (drainage)/20-22 Fr (reinfusion) cannulas and a $1.8 \mathrm{~m}^{2}$ oxygenator (CardioHelp HLS 7.0 oxygenator; Maquet $\mathrm{GmbH}$, Rastatt, Germany). For patients with acceptable oxygenation but under aggressive ventilation or with uncontrolled hypercapnia, high-flow $\mathrm{ECCO}_{2} \mathrm{R}$ therapy was proposed using a jugulojugular ipsilateral configuration as first line: 19-21 Fr (drainage)/16 Fr (reinfusion) cannulas and a 1.3 $\mathrm{m}^{2}$ oxygenator (CardioHelp HLS 5.0 oxygenator; Maquet $\mathrm{GmbH}$ ). Minimal pump flow was established at $2 \mathrm{~L} / \mathrm{min}$ in our protocol.

\section{Data Collection}

The following data were abstracted retrospectively from medical records and intensive care unit (ICU) monitoring records: demographics, medical history, occurrence of organ dysfunction (APACHE2 score; SOFA score), indications and characteristics of extracorporeal respiratory support as well as related complications. In addition, mechanical ventilatory parameters, vv-ECMO therapy parameters, and biology were extracted every $12 \mathrm{~h}$. Blood gases were measured with an ABL90 Flex Plus blood gas analyser (Radiometer, Copenhagen, Denmark). Details of the duration of mechanical ventilation and extracorporeal respiratory support therapy, tracheotomy needs, length of ICU and hospital stay, survival on discharge and cause of death were collected.

\section{Study Definitions}

Baseline data were the values before initiation of extracorporeal respiratory support therapy. $\mathrm{D} 1_{\mathrm{A}}$ was considered as the first measure within 12 hours after extracorporeal respiratory support (initiation or oxygenator change), and $\mathrm{D} 1_{\mathrm{B}}$ as the consecutive measure $12 \mathrm{~h}$ later, and so on.

The decarboxylation index was defined as the product $\mathrm{BF} \times \mathrm{GF}$ and expressed in $\mathrm{L}^{2} / \mathrm{min}^{2}$.

$\mathrm{CO}_{2}$ removal through the membrane oxygenator expressed in $\mathrm{mL} / \mathrm{min}$ was assessed using the standard formula: $\mathrm{CO}_{2}$ removal $=\left({ }_{c t} \mathrm{CO}_{2 \text {-in }}-{ }_{c t} \mathrm{CO}_{2 \text {-out }}\right) \times \mathrm{BF} \times 10 / 1000$. Normalized $\mathrm{CO}_{2}$ removal was calculated by normalizing the partial pressure of carbon dioxide before the lung membrane to $45 \mathrm{mmHg}$ as described previously. ${ }^{20}$

The mechanical ventilation reduction (MVR) ratio was defined as the percentage of reduction of expired minute ventilation compared with the value before initiation of extracorporeal respiratory support. 


\section{Statistical Analysis}

The characteristics of the patients at baseline are reported as percentages for categorical variables and as medians (interquartile range [IQR]) for continuous variables. Categorical variables were compared with the chi-squared test, and continuous variables were compared with a Wilcoxon test. After presenting the cohort and extracorporeal therapies, each oxygenator was analysed independently from its rank of use to consider possible alterations in oxygenator gas exchanges. To minimize the risk of underestimating $\mathrm{CO}_{2}$ removal or the performance of the decarboxylation index caused by extracorporeal respiratory support membrane alteration, the data analysis was focused on the 7 first days. Moreover, analysis of the decarboxylation index in the range $20-30 \mathrm{~L}^{2} / \mathrm{min}^{2}$ was performed because this range of values corresponds to the maximum dose under high-flow $\mathrm{ECCO}_{2} \mathrm{R}$ therapy $(\mathrm{BF}, 2-3 \mathrm{~L} / \mathrm{min} ; \mathrm{GF}, 10 \mathrm{~L} / \mathrm{min})$.

Thereafter, the relationship between the decarboxylation index and $\mathrm{CO}_{2}$ removal was studied as our primary endpoint. The association between these two variables was assessed through a linear regression model to highlight the direct potentiation of BF and GF under extracorporeal respiratory support. Homoscedasticity and the distribution of the residuals were assessed graphically to confirm the robustness of the regression analysis. Adjustment of the model was assessed using $\mathrm{R}^{2}$ and the BlandAltman approach; predicted and observed values were thus compared; the mean of differences was the mean bias and the standard deviation of these differences represented the dispersion. The relationship between the decarboxylation index and the MVR ratio was studied to highlight the direct clinical consequences of the decarboxylation index. Because visual analysis of the repartition showed two distinct phases separated by a threshold of the decarboxylation index $\left(25 \mathrm{~L}^{2} / \mathrm{min}^{2}\right)$, we chose to perform two linear regression models a posteriori to increase the accuracy of the modelling: one for decarboxylation index values $<25 \mathrm{~L}^{2} / \mathrm{min}^{2}$, another for values $>25 \mathrm{~L}^{2} / \mathrm{min}^{2}$. Statistical analysis was performed using XLSTAT Pro 5.7.2 (Addinsoft, New York, USA). A $P$ value $\leq 0.05$ indicated significance.

\section{Results}

\section{Patient Characteristics and Management}

Among the 24 patients who benefited from extracorporeal respiratory support during the study period, 6 were excluded: 3 patients due to premature death and 3 due to missing data. Eighteen patients were included in the final analysis (APACHE2 $=57$ [IQR, 40-70], SOFA at vv-ECMO initiation $=11.6$ [IQR, 913.8]). Reasons for hospitalization were bacterial pneumonia (8 of 18,44\%), severe trauma (8 of 18 , $44 \%$ ), pulmonary embolism ( 1 of $18,5 \%$ ), others ( 1 of $18,5 \%$ ). The main characteristics and demographics of the patients, as well as ventilatory parameters and blood gases before initiation of extracorporeal respiratory support are presented in Table 1.

Thirteen patients $(72 \%)$ were treated initially with vv-ECMO, and $5(28 \%)$ were treated with high-flow $\mathrm{ECCO}_{2} \mathrm{R}$. Duration of mechanical ventilation, ICU stay and total hospital stay were 25 days (IQR, 11-34 
days), 36 days (IQR, 11-46 days), 48 days (IQR, 13-69 days), respectively for $18 \mathrm{~m}^{2}$ oxygenators. Corresponding values for $1.3 \mathrm{~m}^{2}$ oxygenators were 14 days (IQR, 6-35 days), 24 days (IQR, 15-46 days), and 58 days (IQR, 56-65 days), respectively. Outcomes, complications, total duration of extracorporeal respiratory support, details of configurations used and changeout procedures are presented in Supplemental Digital Content 1.

\section{Extracorporeal Respiratory Support and Mechanical Ventilation Changes}

For $1.8 \mathrm{~m}^{2}$ oxygenators, extracorporeal parameters at $\mathrm{D} 1_{\mathrm{A}}$ were $\mathrm{BF} 4.3 \mathrm{~L} / \mathrm{min}(\mathrm{IQR}, 3.5-5.0 \mathrm{~L} / \mathrm{min})$, GF 4 $\mathrm{L} / \mathrm{min}(\mathrm{IQR}, 5-6 \mathrm{~L} / \mathrm{min})$, resulting in a median decarboxylation index of $23.4 \mathrm{~L}^{2} / \mathrm{min}^{2}$ (IQR, $12.0-30.8$ $\left.\mathrm{L}^{2} / \mathrm{min}^{2}\right)$. Extracorporeal therapy allowed a clinically significant reduction of mechanical ventilation from baseline to $\mathrm{D} 1_{\mathrm{A}}: \mathrm{V}_{\mathrm{T}}-3.3 \mathrm{~mL} / \mathrm{kg}(\mathrm{IQR}, 0.3-4 \mathrm{~mL} / \mathrm{kg})$; respiratory rate (RR) -15 cycles $/ \mathrm{min}(\mathrm{IQR}, 4.5-16.5$ cycles/min); $\mathrm{P}_{\mathrm{PLAT}}-7 \mathrm{cmH}_{2} \mathrm{O}$ (IQR, 0.7-14.5 $\left.\mathrm{cmH}_{2} \mathrm{O}\right)$; driving pressure $-5.5 \mathrm{cmH}_{2} \mathrm{O}\left(\mathrm{IQR}, 0-12.7 \mathrm{cmH}_{2} \mathrm{O}\right)$; $\mathrm{VM}_{\mathrm{E}}-7.2 \mathrm{~L} / \mathrm{min}\left(\mathrm{IQR}, 2.4-10.1 \mathrm{~L} / \mathrm{min}\right.$ ) leading to an MVR of $88 \%$; values for crude and normalized $\mathrm{CO}_{2}$ removal were $393 \mathrm{~mL} / \mathrm{min}$ (IQR, 310-526 mL/min) and $385 \mathrm{~mL} / \mathrm{min}$ (IQR, 203-524 mL/min), respectively. During the first week, these parameters were stable globally (Figure 1). Paired BF and GF are presented in (Figure 2). $\mathrm{PaCO}_{2}$ during the first week of extracorporeal therapy was $<35 \mathrm{mmHg}$ for $11 \%$ of samples (27 of 251 ) and $>45 \mathrm{mmHg}$ for $26 \%$ of samples (67 of 251 ).

For $1.3 \mathrm{~m}^{2}$ oxygenators, the extracorporeal parameters at $\mathrm{D} 1_{\mathrm{A}}$ were $\mathrm{BF} 2 \mathrm{~L} / \mathrm{min}(\mathrm{IQR}, 1.8-2.5 \mathrm{~L} / \mathrm{min}), \mathrm{GF} 8$ $\mathrm{L} / \mathrm{min}$ (IQR, 6.5-9 L/min), resulting in a median decarboxylation index of $15 \mathrm{~L}^{2} / \mathrm{min}^{2}(\mathrm{IQR}, 14.5-19.9$ $\left.\mathrm{L}^{2} / \mathrm{min}^{2}\right)$. Extracorporeal therapy allowed a clinically significant reduction of mechanical ventilation from baseline to $D 1_{A}: V_{T}-2.1 \mathrm{~mL} / \mathrm{kg}(\mathrm{IQR}, 1.4-2.2 \mathrm{~mL} / \mathrm{kg}) ; \mathrm{RR}-10$ cycles/min (IQR, 8-10 cycles/min); $\mathrm{P}_{\mathrm{PLAT}}$ $-4 \mathrm{cmH}_{2} \mathrm{O}\left(\mathrm{IQR}, 2-13 \mathrm{cmH}_{2} \mathrm{O}\right)$; driving pressure $-8 \mathrm{cmH}_{2} \mathrm{O}\left(\mathrm{IQR}, 5-14 \mathrm{cmH}_{2} \mathrm{O}\right) ; \mathrm{VM}_{\mathrm{E}}-6.5 \mathrm{~L} / \mathrm{min}(\mathrm{IQR}$, 6.2-8 L/min) leading to an MVR of $76 \%$; values for crude and normalized $\mathrm{CO}_{2}$ removal were $179 \mathrm{~mL} / \mathrm{min}$ (IQR, $165-235 \mathrm{~mL} / \mathrm{min}$ ) and $171 \mathrm{~mL} / \mathrm{min}(\mathrm{IQR}, 157-235 \mathrm{~mL} / \mathrm{min})$, respectively. During the first week, these parameters were stable globally (Figure 1). $\mathrm{PaCO}_{2}$ during the first week of extracorporeal therapy was $<35 \mathrm{mmHg}$ in $7 \%$ of samples (4 of 59 ) and $>45 \mathrm{mmHg}$ in $32 \%$ of samples ((19 of 59 ).

\section{Specific Thresholds for a Decarboxylation Index of 20-30 $\mathrm{L}^{2} / \mathrm{min}^{2}$}

A decarboxylation index of $20 \mathrm{~L}^{2} / \mathrm{min}^{2}$ was associated with an MVR ratio between $38 \%$ and $60 \%$ for 1.8 $\mathrm{m}^{2}$ oxygenators and between $37 \%$ and $71 \%$ for $1.3 \mathrm{~m}^{2}$ oxygenators, while maintaining physiological $\mathrm{PaCO}_{2}$ values (Figure 1). Corresponding values for a decarboxylation index of $30 \mathrm{~L}^{2} / \mathrm{min}^{2}$ were $58 \%-82 \%$ and $55 \%-73 \%$, respectively. 


\section{Decarboxylation Index and Prediction of $\mathrm{CO}_{2}$ Removal}

The decarboxylation index had a linear association with $\mathrm{CO}_{2}$ removal, with the $1.8 \mathrm{~m}^{2}$ oxygenator $\left(\mathrm{R}^{2}\right.$ $=0.62, P<0.001)$ and the $1.3 \mathrm{~m}^{2}$ oxygenator $\left(\mathrm{R}^{2}=0.77, P<0.001\right)$ (Figure 3$)$; for each supplementary unit of the decarboxylation index, the $\mathrm{CO}_{2}$ removal value increased 7 and $8 \mathrm{ml} / \mathrm{min}$, respectively. Comparing the observed and predicted values provided by linear regression models, mean bias were -3 $\mathrm{mL} / \mathrm{min}$ and $-2 \mathrm{~mL} / \mathrm{min}$; dispersions were $85 \mathrm{~mL} / \mathrm{min}$ and $27 \mathrm{~mL} / \mathrm{min}$, respectively (Figure 3).

\section{Decarboxylation Index and Prediction of MVR Ratio}

Similarly, the decarboxylation index was found to be linearly associated with the MVR ratio using the 1.8 $\mathrm{m}^{2}$ and $1.3 \mathrm{~m}^{2}$ oxygenators. For $1.8 \mathrm{~m}^{2}$ oxygenators, two linear regression models were built according to the decarboxylation index value. For values $<25 \mathrm{~L}^{2} / \mathrm{min}^{2}$, each supplementary unit of decarboxylation index was associated with a supplementary MVR ratio of $2 \%$ ( $Y=2 \times$ decarboxylation index $+20 \%$; $P<$ $0.001)$, whereas for values $>25 \mathrm{~L}^{2} / \mathrm{min}^{2}$, this increase was only of $0.5 \%(Y=0.5 \times$ decarboxylation index + $50 \% ; P<0.001$ ) (Figure 4). The $\mathrm{R}^{2}$ value for each model was 0.72 and 0.63 , the mean bias was $1 \%$ and $3 \%$, and the dispersion was $6 \%$ and $3 \%$, respectively. For $1.3 \mathrm{~m}^{2}$ oxygenators, only one linear regression was considered. Each supplementary unit of the decarboxylation index was associated with a supplementary MVR ratio of $1.5 \%$ ( $Y=1.5 \times$ decarboxylation index $+20 \% ; P<0.001)$ with an $\mathrm{R}^{2}$ value of 0.62 , a mean bias of $3 \%$ and a dispersion of $9 \%$ (Figure 4 ).

\section{Discussion}

The present series focused specifically on the determinant of blood decarboxylation under vv-ECMO (1.8 $\mathrm{m}^{2}$ oxygenators) and high-flow $\mathrm{ECCO}_{2} \mathrm{R}$ (1.3 $\mathrm{m}^{2}$ oxygenators). Our study aimed to characterize the relationship between the $\mathrm{BF} \times \mathrm{GF}$ product, named decarboxylation index, and $\mathrm{CO}_{2}$ removal under extracorporeal respiratory support, as well as the reduction of minute ventilation. The primary finding is that the decarboxylation index is linearly associated with extracorporeal $\mathrm{CO}_{2}$ removal with $1.8 \mathrm{~m}^{2}$ oxygenators, as well as $1.3 \mathrm{~m}^{2}$ oxygenators, in the BF range of $1.5-6.8 \mathrm{~L} / \mathrm{min}$; our linear regression models demonstrated a good adjustment $\left(R^{2}=0.62\right.$ for $1.8 \mathrm{~m}^{2}$ oxygenators, $R^{2}=0.77$ for $1.3 \mathrm{~m}^{2}$ oxygenators) with low mean bias, suggesting a strong association between these two variables. The direct clinical consequence is that the decarboxylation index can predict minute ventilation reduction while maintaining $\mathrm{PaCO}_{2}$ at physiological values. The linear regression models also showed good adjustment for $1.8 \mathrm{~m}^{2}$ oxygenators $\left(R^{2}=0.72\right.$ and 0.63$)$, as well as $1.3 \mathrm{~m}^{2}$ oxygenators $\left(R^{2}=0.62\right)$ with significance. Our work therefore highlights that the decarboxylation index is a simple and reliable indicator for predicting the amount of blood decarboxylation under extracorporeal respiratory support and the potential of MVR. Moreover, based on these observations, the present analysis also supports that significant BF values must be used by clinicians to obtain an effective decarboxylation index, and 
therefore clinically relevant $\mathrm{CO}_{2}$ removal. Values in the range $20-30 \mathrm{~L}^{2} / \mathrm{min}^{2}$ were associated with an MVR ratio between $38 \%$ and $58 \%$ for $1.8 \mathrm{~m}^{2}$ oxygenators and between $37 \%$ and $55 \%$ for $1.3 \mathrm{~m}^{2}$ oxygenators.

Blood decarboxylation by extracorporeal respiratory support is used increasingly as a therapeutic option in many clinical situations, either to avoid invasive mechanical ventilation or to reduce its well-known harmful effects. ${ }^{21}$ It has been demonstrated in the case of ARDS that decreasing $V_{T}$, airway pressures (driving pressure, $\mathrm{P}_{\mathrm{PLAT}}$ ) or RR while controlling $\mathrm{PaCO}_{2}$ under mechanical ventilation is associated with a better outcome. ${ }^{22-25}$ Development of these concepts led to a strategy of ultraprotective mechanical ventilation associated with extracorporeal respiratory support for patients with severe ARDS to reduce VILI. 11,26,27 Different devices may thus be used for this specific purpose, with various membrane surfaces and diverse ranges of extracorporeal $\mathrm{BF}$, two main determinants of extracorporeal $\mathrm{CO}_{2}$ removal. Although $\mathrm{ECCO}_{2} \mathrm{R}$ has shown its efficacy for blood decarboxylation in different clinical settings, some studies revealed the modest potential of MVR when low BFs $(<1 \mathrm{~L} / \mathrm{min})$ are used; $\mathrm{V}_{\mathrm{T}}$ values were modestly decreased in these works, requiring maintenance of a high RR (25-30 cycles per minute) to control $\mathrm{PaCO}_{2} \cdot{ }^{28,29}$ Moreover, a non-negligible number of these patients experienced significant hypercapnia. The use of low BF appears to be a main cause of these failures. Accordingly, a recent secondary analysis has highlighted that the use of higher BFs (around $1 \mathrm{~L} / \mathrm{min}$ ) combined with larger oxygenator surfaces $(1.3$ $\mathrm{m}^{2}$ ) is more effective to apply ultraprotective ventilator settings. ${ }^{30}$ These observations were also confirmed by Hermann et al. ${ }^{18}$ who demonstrated that $\mathrm{CO}_{2}$ removal increased when the $\mathrm{BF}$ increased from 0.5 to $2 \mathrm{~L} / \mathrm{min}$. Therefore, the optimal value of $\mathrm{BF}$ required under $\mathrm{ECCO}_{2} \mathrm{R}$ therapy has still to be determined. The answer depends probably on the patient's characteristics (pulmonary dead space, intrinsic $\mathrm{CO}_{2}$ production, etc.) and the objectives of MVR. ${ }^{31}$

In addition to the $\mathrm{BF}, \mathrm{GF}$ is also strongly correlated with $\mathrm{CO}_{2}$ removal. ${ }^{14}$ Its value is usually between 0.5 and $12 \mathrm{~L} / \mathrm{min}$ in most extracorporeal respiratory support devices. The influence of GF on blood decarboxylation potential is well known to strongly depend on the $\mathrm{BF}$ value; with a low $\mathrm{BF}$, the relationship rapidly reaches a plateau, whereas with a $\mathrm{BF}$ higher than $1 \mathrm{~L} / \mathrm{min}$, the association $\mathrm{GF}-\mathrm{CO}_{2}$ removal seems to be more linear. ${ }^{18}$ Thus, the interdependency between BF and GF to predict blood decarboxylation has been highlighted in the literature, however no work has directly studied the product of these two variables. The present study was done to demonstrate that the decarboxylation index (BF $x$ GF) is the cornerstone of blood decarboxylation achieved under extracorporeal respiratory support. One of the main strengths of our work is disposal of most of the inlet and outlet blood gases (sampled every $12 \mathrm{~h}$ ), especially in a high BF under ECMO therapies where data on $\mathrm{CO}_{2}$ removal are scarce. Thus, a linear association has been demonstrated in our work to predict $\mathrm{CO}_{2}$ removal, as well as the MVR ratio. However, these findings are applicable for $\mathrm{BF}$ ranging from 2 to $6.8 \mathrm{~L} / \mathrm{min}$ in $\mathrm{vv}-\mathrm{ECMO}$ and from 1.7 to 3.2 $\mathrm{L} / \mathrm{min}$ in $\mathrm{ECCO}_{2} \mathrm{R}$, resulting in a decarboxylation index ranging from 2 to $68 \mathrm{~L}^{2} / \mathrm{min}^{2}$. More than a physiological reflection about $\mathrm{CO}_{2}$ elimination, our analysis provides a clinical translation in terms of 
mechanical ventilation to reduce dynamic stress induced by aggressive mechanical ventilation, which is probably one of the major challenges in patients with ARDS for the next decade. Furthermore, maintaining physiological $\mathrm{PaCO}_{2}$ may also be crucial in many other pathologies such as massive airway leaks or total major bronchospasm where mechanical ventilation will fail. Our series demonstrates that vv-ECMO and $\mathrm{ECCO}_{2} \mathrm{R}$ should not be thought of in opposition but as a continuum in terms of the amount of extracorporeal blood decarboxylation. Differences in the membrane surface influence $\mathrm{CO}_{2}$ removal, but this was not considerable in our work (Figure 3 ). Note that when $V_{T}$ decreased to very low values (nearapnoeic ventilatory strategy), the influence of an anatomical dead space component becomes dominant in the alveolar dead space fraction, explaining the lower ability to decrease mechanical ventilation with a given decarboxylation index. This justified performing two linear regressions to predict $\mathrm{CO}_{2}$ removal under ECMO therapy.

To highlight the boundary between high-flow $\mathrm{ECCO}_{2} \mathrm{R}$ and vv-ECMO, we specifically assessed the 20-30 $\mathrm{L}^{2} / \mathrm{min}^{2}$ range. These values of the decarboxylation index, corresponding to a $\mathrm{BF}$ of $2-3 \mathrm{~L} / \mathrm{min}$ and a GF of $10 \mathrm{~L} / \mathrm{min}$, allowed an MVR ratio of $38 \%$ to $58 \%$ for $1.8 \mathrm{~m}^{2}$ oxygenators and $37 \%$ to $55 \%$ for $1.3 \mathrm{~m}^{2}$ oxygenators. However, despite the use of a consistent level of blood decarboxylation, our results reveal that ultraprotective ventilation may be not reached for a non-negligible number of patients. Based on this observation, we assume that jugulo-jugular high-flow $\mathrm{ECCO}_{2} \mathrm{R}$ with a set $\mathrm{BF}$ around $2-3 \mathrm{~L} / \mathrm{min}$ is an acceptable compromise in the absence of hypoxaemia, allowing a sufficient amount of extracorporeal blood decarboxylation. This double cannulation configuration offers sufficient diameter and a low impedance allowing a stable extracorporeal BF, limited recirculation phenomena and low haemolysis. In our opinion, this percutaneous approach has an acceptable benefits/risks ratio for these severe critically ill patients while providing an optimal $\mathrm{BF}$. Furthermore, jugulo-jugular high-flow $\mathrm{ECCO}_{2} \mathrm{R}$ may be simply converted to a femoro-jugular V-VV ECMO configuration in the case of delayed refractory hypoxaemia. Future studies will be needed to assess the real benefits of this particular configuration in patients with ARDS, as well as the superiority of ultraprotective ventilation strategies under extracorporeal respiratory support.

Our study has several limitations. First, it is a single-centre retrospective design, with limited extrapolation and missing data. Second, data on the estimated pulmonary dead space fraction before extracorporeal respiratory support initiation, an important determinant of $\mathrm{CO}_{2}$ removal, were not available. Third, the performance of membrane gas exchange of the extracorporeal respiratory support was considered stable during extracorporeal therapy and might influence the results. This justified data collection only during the first week. ${ }^{32}$ Finally, the present series included different clinical situations and different configurations of extracorporeal respiratory support. However, we assume that our analysis provides a global tool to understand the level of extracorporeal decarboxylation.

\section{Conclusions}


Our findings support that the decarboxylation index is a simple and reliable indicator to estimate $\mathrm{CO}_{2}$ removal under extracorporeal respiratory support. The decarboxylation index may also predict the potential of MVR and should be considered more in clinical practice. Our study highlights that a decarboxylation index $>20 \mathrm{~L}^{2} / \mathrm{min}^{2}$ could be insufficient to achieve an ultraprotective ventilation, suggesting that a $B F<2 L / m i n$ does not lead to the necessary level of extracorporeal blood decarboxylation in several patients. Further studies on extracorporeal respiratory support are necessary to confirm our assumptions and to understand the precise targets of BF necessary in clinical practice.

\section{Declarations}

Support was provided only from institutional sources.

No conflict of interest is declared.

\section{Ethical Approval And Consent to participate}

Local ethics committee agreement (IRB number 202000662, Montpellier University Hospital) was obtained. Consent to participate was no requested in agreement with the French health research laws in retrospective design studies.

\section{Consent for publication}

Consent for publication is given by all authors.

\section{Availability of supporting data}

Supporting data are fully available on request.

\section{Competing interests}

The authors declare that there is no conflict of interest.

\section{Funding}

The authors received no financial support for the research and/or authorship of this article.

\section{Author's contributions}

$\mathrm{PD}, \mathrm{MG}, \mathrm{OM}, \mathrm{CM}, \mathrm{HW}$ retrieved the data. TL and JC performed the study draft and statistical analysis of the data. TL and JC wrote the manuscript, which was reviewed by EC, GD and XC. All authors contributed to critical reading of the text and its revision. All authors read and approved the final manuscript.

\section{Acknowledgements}

No specific acknowledgement are made by the authors. 


\section{References}

1. Combes A, Peek GJ, Hajage D, et al: ECMO for severe ARDS: systematic review and individual patient data meta-analysis. Intensive Care Med 46: 2048-2057, 2020.

2. Schmidt M, Hodgson C, Combes A: Extracorporeal gas exchange for acute respiratory failure in adult patients: a systematic review. Crit Care 19: 99, 2015.

3. Rozencwajg S, Guihot A, Franchineau G, et al: Ultra-protective ventilation reduces biotrauma in patients on venovenous extracorporeal membrane oxygenation for severe acute respiratory distress syndrome. Crit Care Med 47: 1505-1512, 2019.

4. Schmidt M, Tachon G, Devilliers $\mathrm{C}$, et al: Blood oxygenation and decarboxylation determinants during venovenous ECMO for respiratory failure in adults. Intensive Care Med 39: 838-846, 2013.

5. Charbit J, Deras P, Courvalin E, et al: Structural recirculation and refractory hypoxemia under femorojugular veno-venous extracorporeal membrane oxygenation. Artif Organs 45: 893-902, 2021.

6. Taccone FS, Malfertheiner MV, Ferrari $\mathrm{F}$, et al: Extracorporeal $\mathrm{CO}_{2}$ removal in critically ill patients: a systematic review. Minerva Anestesio/ 83: 762-772, 2017.

7. Terragni PP, Del Sorbo L, Mascia L, et al: Tidal volume lower than $6 \mathrm{ml} / \mathrm{kg}$ enhances lung protection: role of extracorporeal carbon dioxide removal. Anesthesiology 111: 826-835, 2009.

8. Batchinsky Al, Jordan BS, Regn D, et al: Respiratory dialysis: reduction in dependence on mechanical ventilation by venovenous extracorporeal $\mathrm{CO}_{2}$ removal. Crit Care Med 39: 1382-1387, 2011.

9. Cove ME, MacLaren G, Federspiel WJ, Kellum JA: Extracorporeal carbon dioxide removal, past present and future. Crit Care 16: 232, 2012.

10. Sklar MC, Beloncle F, Katsios CM, Brochard L, Friedrich JO: Extracorporeal carbon dioxide removal in patients with chronic obstructive pulmonary disease: a systematic review. Intensive Care Med 41: 17521762, 2015.

11. Combes A, Fanelli V, Pham T, Ranieri VM; European Society of Intensive Care Medicine Trials Group and the "Strategy of Ultra-Protective lung ventilation with Extracorporeal $\mathrm{CO}_{2}$ Removal for New-Onset moderate to severe ARDS" (SUPERNOVA) investigators: Feasibility and safety of extracorporeal $\mathrm{CO}_{2}$ removal to enhance protective ventilation in acute respiratory distress syndrome: the SUPERNOVA study. Intensive Care Med 45: 592-600, 2019.

12. Bein T, Weber-Carstens $S$, Goldmann A, et al: Lower tidal volume strategy $(\approx 3 \mathrm{ml} / \mathrm{kg})$ combined with extracorporeal $\mathrm{CO}_{2}$ removal versus 'conventional' protective ventilation $(6 \mathrm{ml} / \mathrm{kg})$ in severe ARDS: the prospective randomized Xtravent-study. Intensive Care Med 39: 847-856, 2013. 
13. Sun L, Kaesler A, Fernando P, Thompson AJ, Toomasian JM, Bartlett RH: $\mathrm{CO}_{2}$ clearance by membrane lungs. Perfusion 33: 249-253, 2018.

14. Strassmann S, Merten M, Schäfer S, et al: Impact of sweep gas flow on extracorporeal $\mathrm{CO}_{2}$ removal (ECCO2R). Intensive Care Med Exp 7: 17, 2019.

15. Karagiannidis C, Kampe KA, Sipmann FS, et al: Veno-venous extracorporeal $\mathrm{CO}_{2}$ removal for the treatment of severe respiratory acidosis: pathophysiological and technical considerations. Crit Care 18: R124, 2014.

16. Zakhary B, Sheldrake J, Pellegrino V: Extracorporeal membrane oxygenation and V/Q ratios: an ex vivo analysis of $\mathrm{CO}_{2}$ clearance within the Maquet Quadrox-iD oxygenator. Perfusion 35(1 suppl): 29-33, 2020.

17. Eloot S, Peperstraete H, De Somer F, Hoste E: Assessment of the optimal operating parameters during extracorporeal $\mathrm{CO}_{2}$ removal with the Abylcap ${ }^{\circledR}$ system. Int J Artif Organs 39: 580-585, 2017.

18. Hermann A, Riss K, Schellongowski $P$, et al: A novel pump-driven veno-venous gas exchange system during extracorporeal $\mathrm{CO}_{2}$-removal. Intensive Care Med 41: 1773-1780, 2015.

19. Lehle K, Philipp A, Hiller K-A, et al: Efficiency of gas transfer in venovenous extracorporeal membrane oxygenation: analysis of 317 cases with four different ECMO systems. Intensive Care Med 40: 18701877, 2014.

20. Wearden PD, Federspiel WJ, Morley SW, et al: Respiratory dialysis with an active-mixing extracorporeal carbon dioxide removal system in a chronic sheep study. Intensive Care Med 38: 1705-1711, 2012.

21. Slutsky AS, Ranieri VM: Ventilator-induced lung injury. N Engl J Med 369: 2126-2136, 2013.

22. Acute Respiratory Distress Syndrome Network, Brower RG, Matthay MA, et al: Ventilation with lower tidal volumes as compared with traditional tidal volumes for acute lung injury and the acute respiratory distress syndrome. N Engl J Med 342: 1301-1308, 2000.

23. Laffey JG, Bellani G, Pham T, et al: Potentially modifiable factors contributing to outcome from acute respiratory distress syndrome: the LUNG SAFE study. Intensive Care Med 42: 1865-1876, 2016.

24. Amato MBP, Meade MO, Slutsky AS, et al: Driving pressure and survival in the acute respiratory distress syndrome. N Engl J Med 372: 747-755, 2015.

25. Aoyama H, Pettenuzzo T, Aoyama K, Pinto R, Englesakis M, Fan E: Association of driving pressure with mortality among ventilated patients with acute respiratory distress syndrome: a systematic review and meta-analysis. Crit Care Med 46: 300-306, 2018. 
26. Abrams D, Schmidt M, Pham T, et al: Mechanical ventilation for acute respiratory distress syndrome during extracorporeal life support. research and practice. Am J Respir Crit Care Med 201: 514-525, 2020.

27. McNamee JJ, Gillies MA, Barrett NA, et al: Effect of lower tidal volume ventilation facilitated by extracorporeal carbon dioxide removal vs standard care ventilation on 90-day mortality in patients with acute hypoxemic respiratory failure: the REST randomized clinical trial. JAMA 326: 1013-1023, 2021

28. Fanelli V, Ranieri MV, Mancebo J, et al: Feasibility and safety of low-flow extracorporeal carbon dioxide removal to facilitate ultra-protective ventilation in patients with moderate acute respiratory distress syndrome. Crit Care 20: 36, 2016.

29. Schmidt M, Jaber S, Zogheib E, Godet T, Capellier G, Combes A. Feasibility and safety of low-flow extracorporeal $\mathrm{CO}_{2}$ removal managed with a renal replacement platform to enhance lung-protective ventilation of patients with mild-to-moderate ARDS. Crit Care 22: 122, 2018.

30. Combes A, Tonetti T, Fanelli V, et al: Efficacy and safety of lower versus higher $\mathrm{CO}_{2}$ extraction devices to allow ultraprotective ventilation: secondary analysis of the SUPERNOVA study. Thorax 74: 1179-1181, 2019.

31. Goligher EC, Combes A, Brodie D, et al: Determinants of the effect of extracorporeal carbon dioxide removal in the SUPERNOVA trial: implications for trial design. Intensive Care Med 45: 1219-1230, 2019.

32. Epis F, Belliato M: Oxygenator performance and artificial-native lung interaction. $J$ Thorac Dis 10(Suppl 5): S596-S605, 2018.

\section{Table}

Table 1. Characteristics of the Patients 


\begin{tabular}{|c|c|c|c|c|}
\hline & Overall $(n=18)$ & $\begin{array}{l}\text { vv-ECMO } \\
(n=13)\end{array}$ & $\begin{array}{l}\text { High-flow } \mathrm{ECCO}_{2} \mathrm{R} \\
(n=5)\end{array}$ & $P$ value \\
\hline Demographics & - & - & - & - \\
\hline Age (years) & $44(32-62)$ & $46(31-65)$ & $42(41-43)$ & 0.62 \\
\hline Male, $n(\%)$ & $14(77)$ & $11(84)$ & $3(60)$ & 0.26 \\
\hline BMI $\left(\mathrm{kg} / \mathrm{m}^{2}\right)$ & $\begin{array}{l}27.3(25.3- \\
30.5)\end{array}$ & $\begin{array}{l}28.3(27- \\
30.9)\end{array}$ & $25.7(23.5-26.6)$ & 0.15 \\
\hline IBW (kg) & $72(66-75)$ & $75(66-75)$ & $66(60-73)$ & 0.42 \\
\hline RESP score & $\begin{array}{l}-1.5(-3.8 \text { to } \\
3.8)\end{array}$ & $-1(-4$ to 3$)$ & $-2(-2.5$ to 0$)$ & 0.51 \\
\hline IGS I| score & $56(40.3-70)$ & $57(50-67)$ & $38(26-73)$ & 0.45 \\
\hline $\begin{array}{l}\text { SOFA score at treatment } \\
\text { initiation }\end{array}$ & $11(9-13.8)$ & $12(10-14)$ & $9(8-9)$ & 0.032 \\
\hline \multicolumn{5}{|l|}{$\begin{array}{l}\text { Cause of ICU admission, } n \\
(\%)\end{array}$} \\
\hline Pneumonia & $8(44)$ & $5(38)$ & $3(60)$ & 0.41 \\
\hline Severe trauma & $8(44)$ & $6(46)$ & $2(40)$ & 0.81 \\
\hline Pulmonary embolism & $1(5)$ & $1(13)$ & $0(0)$ & 0.52 \\
\hline Allergic bronchospam & $1(5)$ & $1(13)$ & $0(0)$ & 0.52 \\
\hline \multicolumn{5}{|l|}{ Ventilatory parameters } \\
\hline $\mathrm{V}_{\mathrm{Te}}(\mathrm{mL} / \mathrm{kg} \mathrm{IBW})$ & $6.4(5.8-6.9)$ & $6.3(5.4-6.5)$ & $6.6(6.0-8.0)$ & 0.26 \\
\hline Respiratory rate (cycles/min) & $26(24-28)$ & $27(25-28)$ & $25(22-28)$ & 0.86 \\
\hline VMe (L/min) & $\begin{array}{l}12.0(8.7- \\
13.9)\end{array}$ & $\begin{array}{l}11.8(9.3- \\
13.1)\end{array}$ & $13.4(8.8-14.2)$ & 0.66 \\
\hline $\mathrm{P}_{\text {PLAT }}\left(\mathrm{cmH}_{2} \mathrm{O}\right)$ & $32(28-36)$ & $34(28-38)$ & $31(31-34)$ & 1 \\
\hline PEEP $\left(\mathrm{cmH}_{2} \mathrm{O}\right)$ & $12(10-14)$ & $12(8-15)$ & $12(12-12)$ & 0.93 \\
\hline Driving pressure $\left(\mathrm{cmH}_{2} \mathrm{O}\right)$ & $20(17-22)$ & $20(15-21)$ & $19(19-22)$ & 0.92 \\
\hline $\mathrm{FiO}_{2}(\%)$ & $100(76-100)$ & $\begin{array}{l}100(100- \\
100)\end{array}$ & $50(50-100)$ & 0.06 \\
\hline Admission-to-MV time (h) & $0.3(0-0.3)$ & $0(0-0.3)$ & $0.3(0.3-4)$ & 0.17 \\
\hline $\begin{array}{l}\text { MV-to-treatment initiation } \\
\text { time (h) }\end{array}$ & $50(5-128)$ & $29(5-156)$ & $71(28-77)$ & 0.69 \\
\hline
\end{tabular}




\begin{tabular}{|lllll|}
\hline Prior prone positioning, $n(\%)$ & $6(33)$ & $5(38)$ & $1(20)$ & 0.45 \\
\hline $\mathrm{PaO}_{2}(\mathrm{mmHg})$ & & & & \\
\hline $\mathrm{PaO}_{2}: \mathrm{FiO}_{2}$ ratio & $65(54-78)$ & $57(53-71)$ & $83(77-140)$ & 0.01 \\
\hline $\mathrm{SaO}_{2}(\%)$ & $71(63-90)$ & $65(54-74)$ & $173(166-253)$ & 0.01 \\
\hline $\mathrm{PaCO}_{2}(\mathrm{mmHg})$ & $90(88-97)$ & $88(87-90)$ & $98(96-99)$ & 0.02 \\
\hline $\mathrm{pH}$ & $54(46-60)$ & $57(44-60)$ & $47(47-60)$ & 1 \\
\hline $\mathrm{HCO}_{3}{ }^{-}(\mathrm{mEq})$ & $7.34(7.20-$ & $7.35(7.19-$ & $7.32(7.31-7.35)$ & 0.31 \\
\hline $\mathrm{Hb}(\mathrm{g} / \mathrm{L})$ & $7.36)$ & $7.41)$ & \\
& $26.9(20.1-$ & $27.9(17.5-$ & $25.8(24-31.2)$ & 0.80 \\
\hline
\end{tabular}

Mann-Whitney or chi $^{2}$ test was used as appropriate. Data are presented as median (IQR) except where indicated otherwise. $\mathrm{BMI}$, body mass index; $\mathrm{ECCO}_{2} \mathrm{R}$, extracorporeal carbon dioxide removal; IBW, ideal body weight; ICU, intensive care unit; MV, mechanical ventilation; RESP, Respiratory Extracorporeal Membrane Oxygenation Survival Prediction; vv-ECMO, veno-venous extracorporeal membrane oxygenation.

\section{Figures}




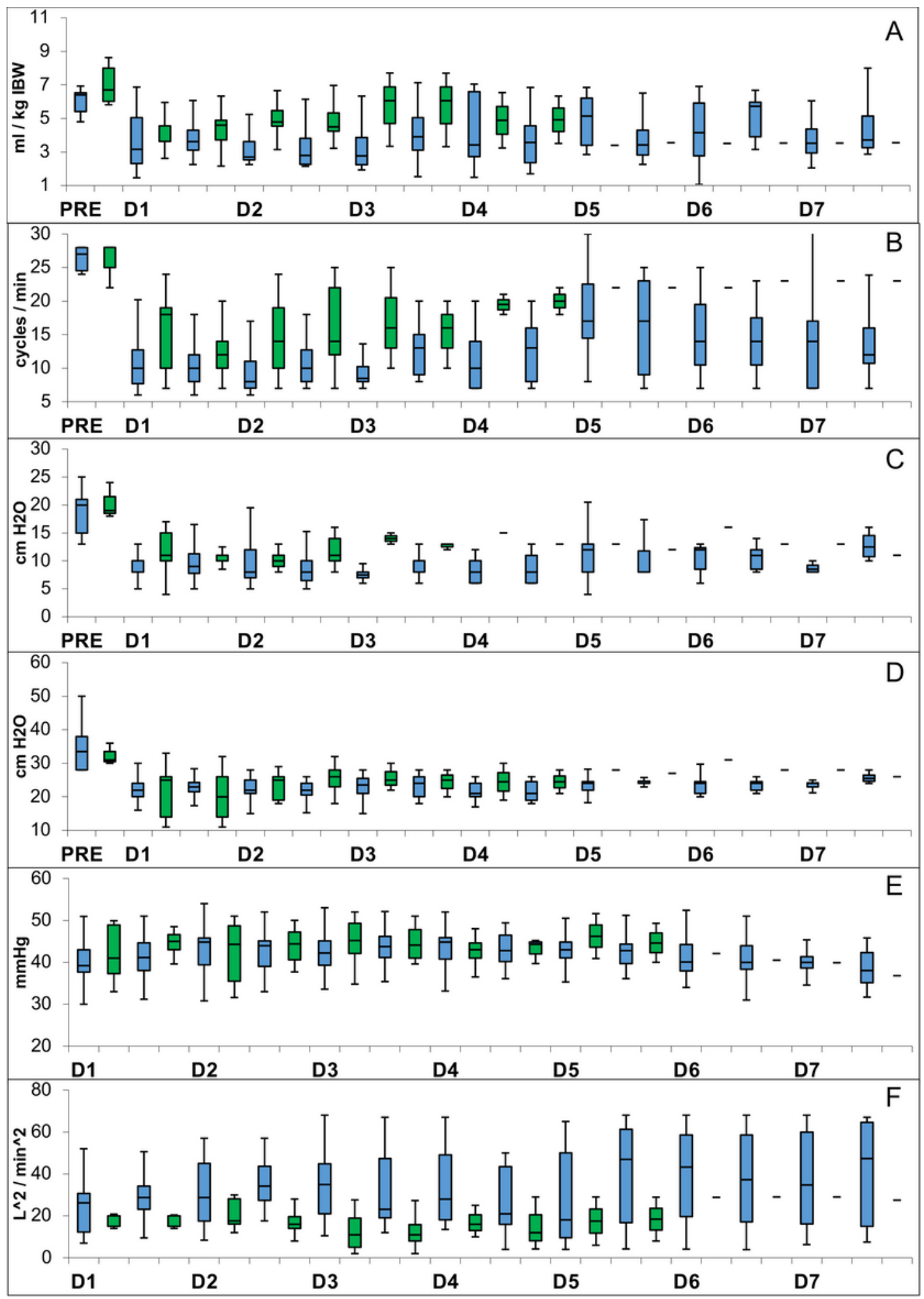

Figure 1

Evolution of $\mathrm{VT}_{\mathrm{e}}(\mathbf{A})$, respiratory rate (B), plateau pressure (C), driving pressure (D), $\mathrm{PaCO}_{2}(\mathrm{E})$, decarboxylation index (F) over the first 7 days of treatment (D1 to D7) for $1.8 \mathrm{~m}^{2}$ oxygenators (blue) and $1.3 \mathrm{~m}^{2}$ oxygenators (green) measured every $12 \mathrm{~h}$. D1, day 1 of treatment; IBW, ideal body weight; PRE, pretreatment parameters. 


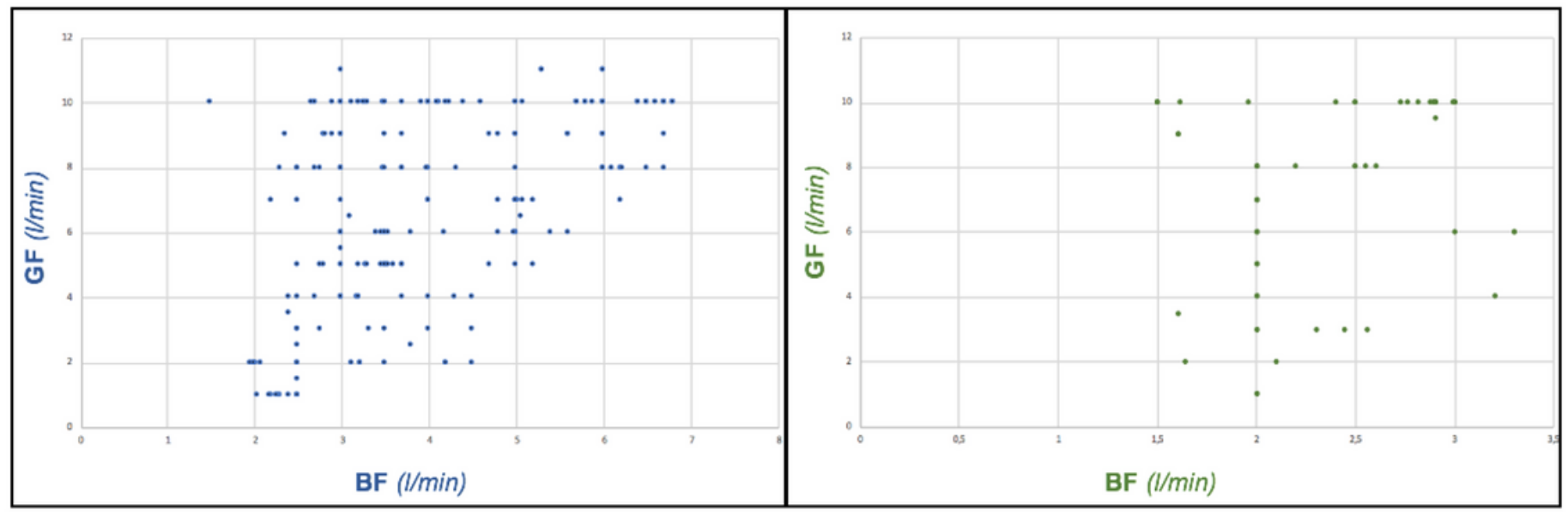

Figure 2

Dispersion for observed BF/GF couples for $1.8 \mathrm{~m}^{2}$ (left, blue) and $1.3 \mathrm{~m}^{2}$ (right, green) oxygenators.

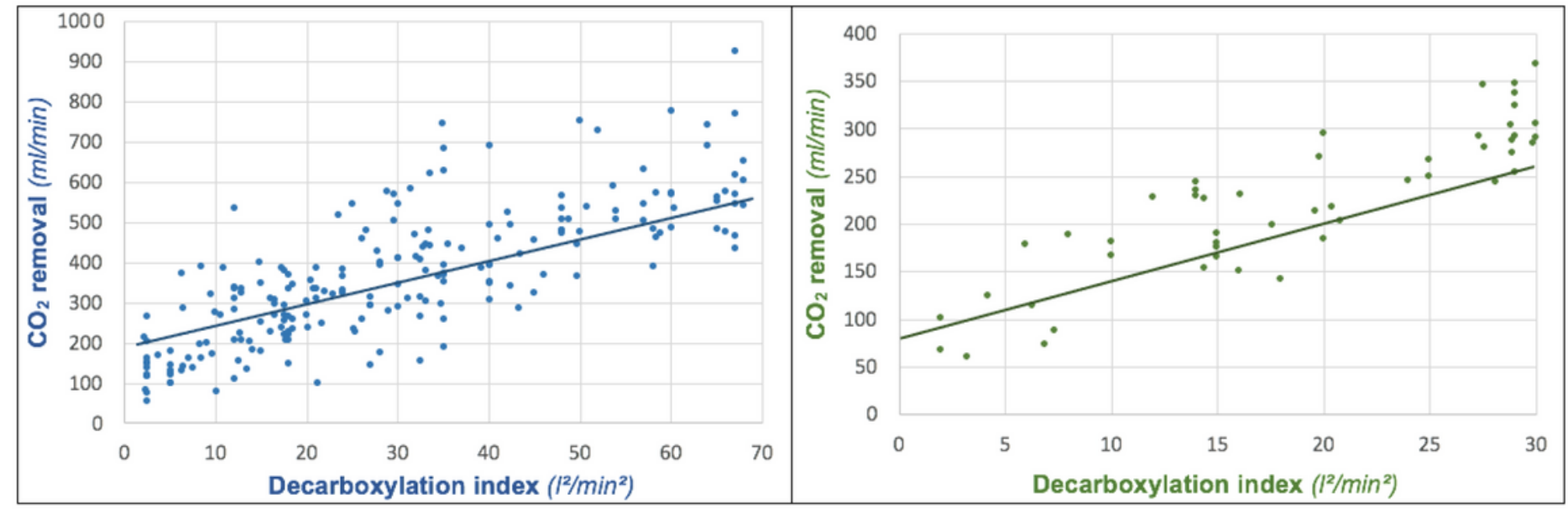

\section{Figure 3}

Linear regression of $\mathrm{CO}_{2}$ removal according to the decarboxylation index for $1.8 \mathrm{~m}^{2}$ oxygenators (left, blue) and $1.3 \mathrm{~m}^{2}$ oxygenators (right, green). The respective equations are as follows: $\mathrm{CO}_{2}$ removal $=7 \times$ decarboxylation index $+160\left(\mathrm{R}^{2}=0.62, \quad P<0.001\right) ; \mathrm{CO}_{2}$ removal $=8 \times$ decarboxylation index $+80\left(\mathrm{R}^{2}\right.$ $=0.77, P<0.001)$. 


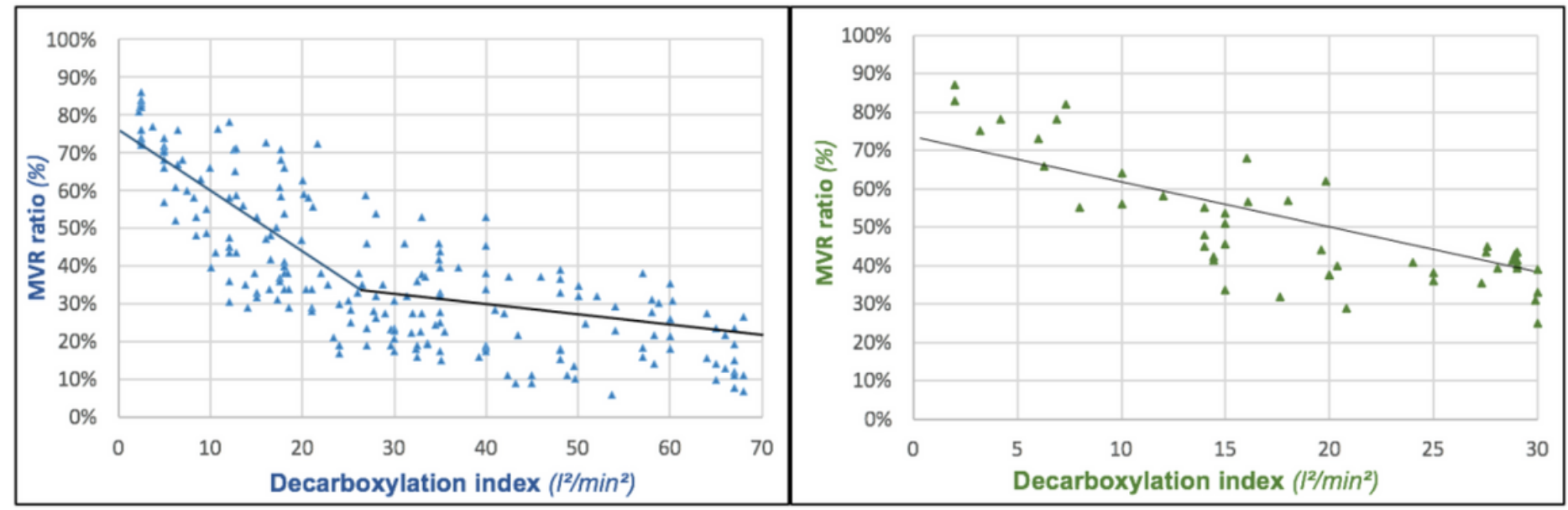

\section{Figure 4}

Linear regression of the mechanical ventilation reduction (MVR) ratio according to the decarboxylation index for $1.8 \mathrm{~m}^{2}$ oxygenators (left, blue) and $1.3 \mathrm{~m}^{2}$ oxygenators (right, green). The respective equations are as follows: MVR ratio $=80 \%-2 \times$ decarboxylation index $<25 \mathrm{~L}^{2} / \mathrm{min}^{2}\left(\mathrm{R}^{2}=0.72, P<0.001\right)$, MVR ratio $=50 \%-0.5 \times$ decarboxylation index $>25 \mathrm{~L}^{2} / \mathrm{min}^{2}\left(\mathrm{R}^{2}=0.63, P<0.001\right)$; MVR ratio $=80 \%-1.5 \times$ decarboxylation index $\left(\mathrm{R}^{2}=0.62, P<0.001\right)$.

\section{Supplementary Files}

This is a list of supplementary files associated with this preprint. Click to download.

- DISupplementalDigitalContent1.docx 